\title{
Importance of Blastocyst Morphology in Selection for Transfer
}

\author{
Borut Kovačič and Veljko Vlaisavljević \\ University Medical Centre Maribor \\ Slovenia
}

\section{Introduction}

Prolonged cultivation of embryos to the blastocyst stage has become a routine practice in the human in vitro fertilization program (IVF) since 1999, when the first commercial sequential media were developed. The culture systems have been improved many times and today most of the blastocyst culture media enable the embryos to reach the blastocyst stage in more than 50\% of cases (Gardner et al., 1998; Kovačič et al., 2004). The advantages of blastocyst culture are in the possibilities for selection of embryos that have an activated genome (Braude et al., 1988), higher predictive values for implantation on the basis of their morphological appearance as compared with earlier embryos (Gardner and Schoolcraft, 1999; Kovačič et al., 2004) and in a reduction in the number of transferred embryos without compromising pregnancy rate (Gardner et al., 2000a). Blastocyst is also a stage that is better synchronized with endometrial receptivity for its implantation (Croxatto et al., 1978; Gardner et al., 2000c). By replacement of embryos in the blastocyst stage, their exposure to hyperstimulated milieu and consequent endometrial contractions, which could be fatal for them, is significantly shortened (Lesny et al., 1998). Blastocysts also contain a larger number of cells than early stage embryos and should therefore have a better possibility of survival of cryopreservation (Veeck, 2003).

\section{Blastocyst culture}

The first synthetic medium of only 9 components for mammalian embryos was developed 50 years ago. Since then, intensive research has continued to develop the optimum chemically defined media for human embryos (Summers and Biggers, 2003). In various parts of the female reproductive tract, a precise biochemical analysis of uterine and Fallopian tubal fluids was carried out and the metabolism of energy substrates has also been studied (Leese et al., 1993; Conagham et al., 1993; Houghton et al., 2002; Gardner et al., 2001). These investigations lead to the development of sequential media for prolonged cultivation of human embryos (Gardner and Lane, 1997). After that, the media have been modified several times by adding other macromolecules, which enhance embryo development and implantation, e.g. EDTA (Gardner et al., 2000b) and hyaluronan (Stojković et al., 2002). Also, the toxicity of the medium occurring due to the degradation of amino acids was decreased by substituting the heat-sensitive glutamine for the more stable alanylglutamine (Lane et al., 2001). By using commercial blastocyst media in the human IVF 
program, a blastocyst development rate should be at least $50 \%$. The blastulation rate and quality of developed blastocysts can be improved by reducing the oxygen concentration in the incubator atmosphere (Kovačič and Vlaisavljević, 2008; Kovačič et al., 2010).

\section{Blastocyst development}

\subsection{Compaction}

An early embryo begins to divide without increasing its volume. After the third mitotic division, a substantial protein biosynthesis is restored and the embryo starts growing. Consequently, the junctions between blastomeres change, leading to the formation of the compact stage. Compaction should normally be completed on the fourth day of its development when the embryo reaches the morula stage (Abe et al., 1999).

The junctions are dynamic and change during mitosis. Compaction represents the beginning of differentiation, followed by polarization of peripheral blastomeres and lost of totipotency. The polarization is induced by junctions with neighbouring blastomeres. Due to embryo growth, the cells lose their oval shape and become more tightly connected to each other. Compaction is therefore a process of forming gap junctions, adherens junctions, tight junctions and desmosomes between blastomeres. Gap junctions are especially important for transport of metabolites and molecules that regulate mitotic divisions (Ducibella et al., 1975). The membranes between the cells are difficult to observe with a light microscope. The abnormally tight junctions lead to exclusion of blastomeres from the formation of a compact embryo (Watson, 1992).

\subsection{Cavitation}

Approximately 24 hours after compaction, the cells start forming a fluid-filled cavity blastocoel. During cavitation, the cells differentiate into the trophectoderm (TE) and inner cell mass (ICM). TE cells maintain cell polarity. Accumulation of water within the blastocoel is a result of $\mathrm{Na}^{+}$transport into the blastocoel. $\mathrm{Na} / \mathrm{K}$ ATPase on basolateral membrane of TE cells pumps intracellular $\mathrm{Na}^{+}$from TE into the blastocoels (Watson and Kidder, 1988). Trophectodermal cells are connected by a small surface area with frequent tight junctions and desmosomes that form a seal between cells and maintain cell polarity. They prevent blastocoel liquid from pouring out and keep sodium ions within the blastocoel. (Gualtieri et al., 1992; Garrod et al., 1996). These ions cause osmotic gradient, which consequently results in the passive diffusion of water molecules into the blastocoel causing the blastocoel to start to grow (Watson, 1992).

The expansion of the blastocoel plays an important role in differentiation between TE and ICM. The ICM cells are non-differentiated and pluripotent and should form a compact and oval formation. Outer membranes of ICM don't have junctions with other cells and communicate directly with blastocoel fluid. They are under the regulation of specific growth factors from the blastocoel that regulate their differentiation into the primitive endoderm. The blastocoel fluid also functions as a culture medium for ICM (Dardik et al., 1993). Its molecular composition mostly depends on TE cells. One of the functions of TE is also in reducing the oxygen concentration in the blastocoel fluid and enabling hypoxic conditions that are required for normal gene transcription in ICM cells (Houghton, 2006). 


\section{Blastocyst scoring systems}

The introduction of blastocyst culture into an IVF program offers the possibility for reducing the number of transferred embryos. But the replacements of more than one blastocyst still results in a very high proportion of multiple pregnancies (Vlaisavljević et al., 2008). For this reason, the tendency for single blastocyst transfer arises and various methods of selecting the optimal blastocyst with good developmental potential have been published. Numerous biochemical studies showed that selection between the blastocysts can be made by evaluating their metabolic activity (Hardy et al., 1989; Conagham et al., 1993; Gardner et al., 2001; Houghton et al., 2002). These biochemical methods are time consuming and require expensive additional laboratory equipment. Besides this, their values in predicting the implantation ability are not higher than values obtained by morphological assessment. Thus, blastocyst morphology evaluation still remains the most frequently-used selection method.

Over the last 20 years, several blastocyst morphology evaluation systems have developed. Dokras et al. (1993) were the first who attempted to define the optimal blastocyst by differentiating them according to whether the blastocoele originated from early cavitation or from several vacuoles. In the early period of human blastocyst culture, many gave the priority for selecting the embryos for transfer to blastocysts with more expanded blastocoeles (Shoukir et al., 1998) and to hatching blastocysts (Balaban et al., 2000; Yoon et al., 2001). Later, Gardner and Schoolcraft (1999) described the new three part scoring system that took three morphologic parameters into consideration: blastocoele expansion, form of inner-cell mass (ICM) and trophectoderm (TE) cohesiveness.

\subsection{Tripartite scoring of blastocysts}

Gardner and Schoolcraft (1999) gave six numerical scores (1-6) to blastocysts regarding the degree of blastocoel expansion and status of hatching. The early blastocysts with the beginning of blastocoel formation are scored as 1 and hatched blastocysts as 6 (Figure 1).
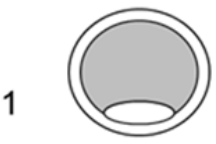
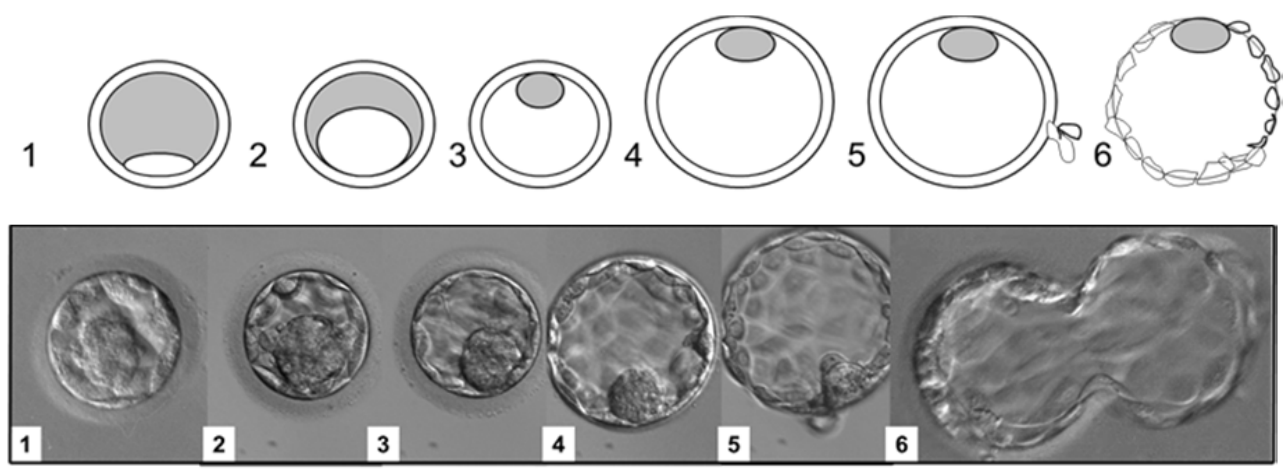

Fig. 1. Expansion and hatching status.

1 The blastocoel cavity represents less than half the volume of the embryo; 2 The blastocoel cavity is more than half the volume of the embryo; 3 Full blastocyst, cavity completely fills the embryo; 4 Expanded blastocyst, cavity is larger than the embryo with thinning of the shell; 5 Hatching out of the shell; 6 Hatched out of the shell. (Gardner \& Schoolcraft, 1999). 
ICM is only possible for assessment of full blastocysts graded 3-6. The ICM and TE were assessed each as A, B or C, where A is the score for optimal morphology and C for severe irregularities observed (Figure 2). By using this scheme, the transfer of blastocysts scored 3AA or greater results in a pregnancy rate of $60 \%$.

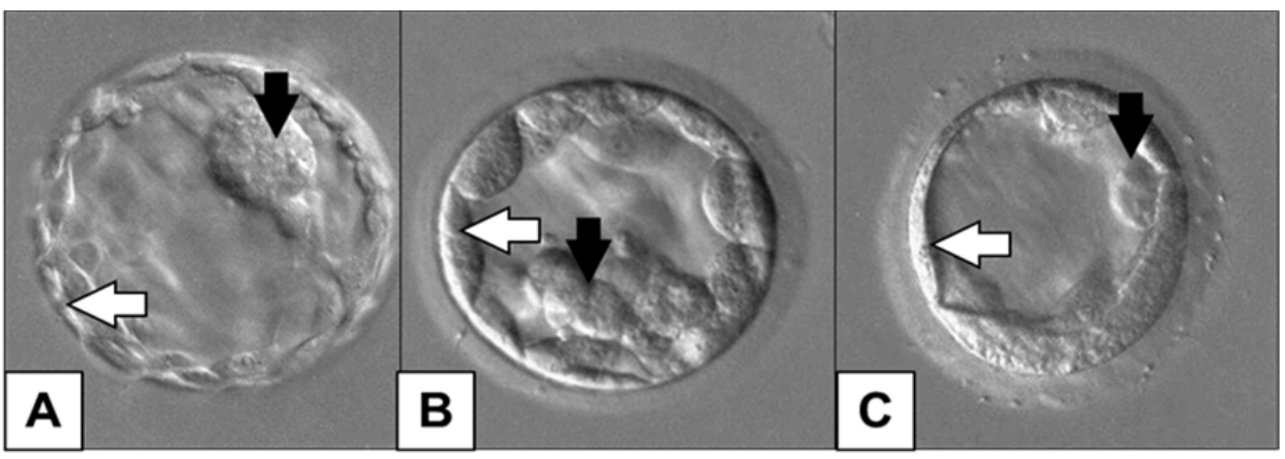

Fig. 2. Inner cell mass (black arrows) and trophectoderm (white arrows) scores.

Inner cell mass:A Many cells, tightly packed; B Several cells, loosely grouped; C Very few cells. Trophectoderm: A Many cells forming a cohesive layer; B Few cells forming a loose epithelium; C Very few large cells. (Gardner \& Schoolcraft, 1999).

Gardner's system has been modified by Cornell's group (Veeck and Zaninović, 2009). The compact embryos with early cavitation and with blastocoels smaller than half the volume of the embryo was considered to be cavitating morulas and not blastocysts. Blastocysts were defined as having blastocoels filling greater than half the volume of the conceptus and should possess cells that suggest the formation of ICM. This means that Score 3 from Gardner's system is equal to Score 1 from Cornell's grading. Blastocysts with slightly thinner zona due to growing of the embryo are graded with Score 2. Score 3 is given to fully expanded blastocysts with thin zona. Scores 4 and 5 are equal to Gardner's Scores 5 and 6 . Grade 6 was given to hatching or hatched blastocysts in which the zona has been opened due to blastomere biopsy or assisted hatching. Besides this, Cornell's system contains four alphabetical grades (A-D) for ICM and four for TE, where D is the score for degenerative ICM or TE.

By transferring one $1 \mathrm{BD}$, an implantation rate of $59 \%$ was achieved, and replacement of one $3 \mathrm{AA}, 3 \mathrm{AB}$ or $3 \mathrm{BA}$, resulted in implantation in $63 \%$ of cases. The difference was not significant and the authors concluded that any defined blastocyst on day 5 will lead to good pregnancy and implantation results. Lower success rates were obtained only after replacement of day-5 morulas $(17 \%)$.

\subsection{Grading of blastocysts}

Too little attention has been given to individual grading parameters, and the main question in the selection process is which of the blastocyst structures is more important for achieving normal pregnancy. A tripartitive scoring system is therefore difficult to use in evaluating the implantation ability of various morphological types of blastocysts. It is not helpful in cycles in which the blastocysts for transfer have to be selected between suboptimal blastocysts. 
From this reason, Kovačič et al. (2004) developed the simple blastocyst grading system. They took four morphological parameters into consideration: expansion of blastocoels, morphology of ICM, cohesiveness of TE and presence of excluded blastomeres or fragments from the formation of blastocysts (Figure 3). This system does not distinguish between different degrees of blastocoel expansion. The authors explained their decision with the fact that the blastocoel can fill and expands in a very short time. They described eight morphological types of day- 5 embryos that are most frequently found in the cohort of vital embryos after prolonged cultivation in vitro. All eight types were ranked for their implantation abilities and live birth rates from B1 to B8 (live birth rates: $45.2 \%, 32.8 \%, 26.9 \%$, $23 \%, 17.7 \%, 16.7 \%, 7.7 \%, 1.2 \%)$. ICM was found to be the most important factor for successful implantation.
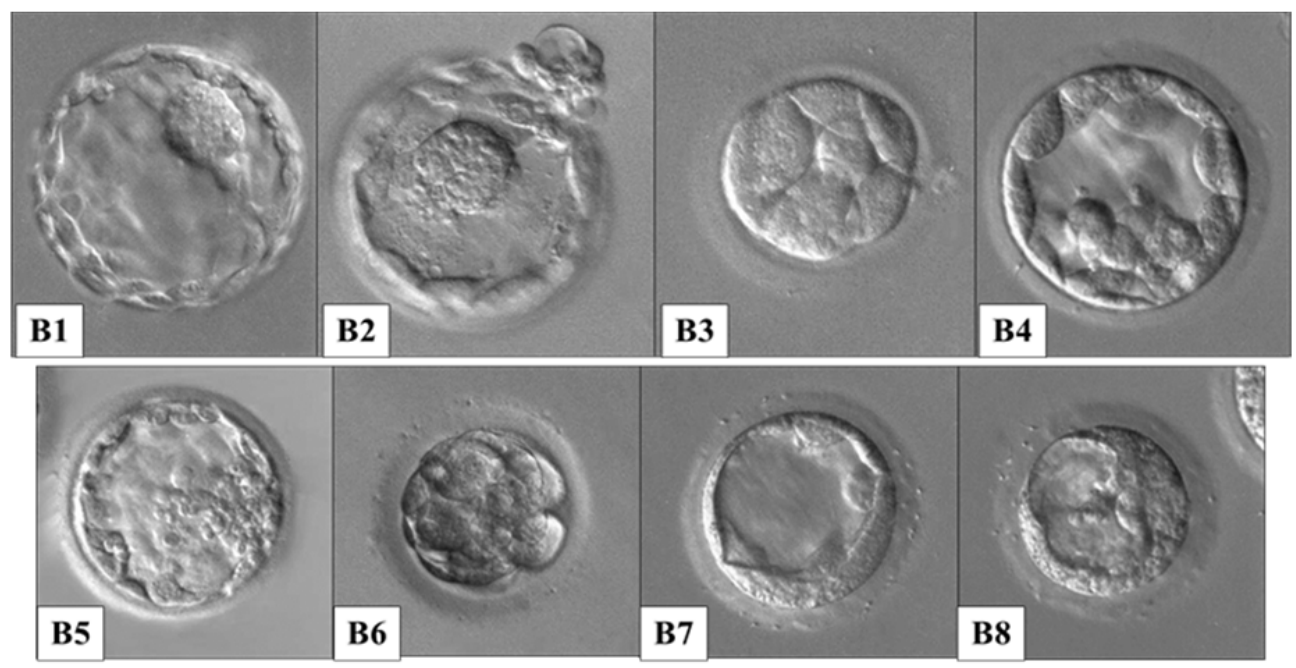

Fig. 3. Grading of blastocysts by Kovacic et al. (2004).

B1 Optimal blastocysts: full or expanded blastocysts with blastocoele filling the entire blastocyst, oval shaped and compact inner-cell mass (ICM) and multicellular cohesive trophectoderm (TE). B2 Expanded blastocysts with normal ICM, but non-optimal (fragmented or necrotic) TE. B3 Unexpanded blastocysts and compact morulae with beginning of cavitation. B4 Expanded blastocysts with normal TE, but non-optimal (noncompact or fragmented) ICM. B5 Expanded blastocysts with non-optimal ICM and TE. B6 Slightly smaller blastocysts with up to $20 \%$ excluded blastomeres or fragments from the formation of blastocyst. B7 Necrotic blastocysts without ICM and with large vacuole instead of blastocoel. B8 Small blastocysts with less than $80 \%$ of embryonic mass transformed into compact morulae or blastocysts.

\subsection{Other morphological characteristics with impact on implantation}

Individual grading parameters were further studied by various groups.

Using morphometry of ICM, Richter et al. (2001) defined optimal blastocysts even more precisely. The authors discredited the previously described tripartitive scoring systems, 
stating that the observed differences using this system reflect differences in developmental timing rather than differences in actual quality. More attention in their own study was given to measuring of ICM size and shape. They found that the ICMs of implanting blastocysts were significantly larger than ICMs of non-implanting ones. A linear positive relationship between ICM size and implantation ability was revealed. Optimal ICM size was defined as measuring $>4500 \mu \mathrm{m}^{2}$ and poor blastocysts with ICM size of $<3800 \mu \mathrm{m}^{2}$ (implantation rates $45 \%$ vs. $32 \%$ ). The ICM shape seems to play an important role in further embryo development as well, since blastocysts with optimal ICM sizes and oval shapes implanted in a higher proportion $(60 \%)$ than the blastocysts with ICMs that were only optimally sized (29\%) or shaped (32\%).

Ebner et al. (2004) found a significant difference in blastocyst implantation rates when the location of herniation during hatching process is positioned in the ICM region or TE region (67\% vs. $41 \%)$.

Between various morphological characteristics with possible influence on further embryo development, cytoplasmic strings that connect ICM with TE (Scott, 2000) and vacuoles in the ICM region were found to decrease implantation ability.

The proportion of cytoplasm excluded from the formation of blastocysts either as blastomeres or fragments is also in correlation with embryo ability to reach a morphologically optimal blastocyst (Ivec et al., 2011).

The effect of delay in development to blastocyst by one day was also analyzed by several groups. It can frequently occur that embryos reach blastocyst stage only on day 6 . The reasons for this phenomenon are not exactly known. It was only hypothesized that cytoplasmic immaturity of oocytes, chromosomal abnormalities in blastomeres and suboptimal culture conditions could cause longer intermitotic periods and, consequently, slower embryo development. Our results (Ivec et al., 2011) showed that $84.4 \%$ of compact day- 5 morulas are able to reach the blastocyst stage, but only $23.9 \%$ of them are morphologically optimal blastocysts.

Day-5 blastocysts usually result in better implantation rate than embryos that are transferred into the uterus as day-6 blastocysts $(37.4 \%$ vs. $20.6 \%$ in Shapiro et al., 2001)(22.1\% vs. $3.6 \%$ in Barrenetxea et al., 2005). However, the implantation rates can be improved when day- 6 blastocysts are frozen and replaced during one of the next fresh cycles (Shapiro et al., 2008).

\section{Blastocyst selection for transfer}

Multiple pregnancies, the usual complications of an IVF program, present a serious perinatal risk for mother and child. The analyses of assisted reproductive technology outcomes from European and American registers reported that one half of children born after IVF/ICSI methods derived from multiple pregnancies (de Mouzon et al., 2010; Schieve et al., 1999).

Such a high rate of multiple pregnancies after IVF has been accepted in the past, since acceptable success rates have been achieved only after the transfer of three or four early cleavage stage embryos. By improving the culture conditions, developing culture media for 
prolonged cultivation of embryos in vitro and by introducing the blastocyst culture, reduction of the number of embryos for transfer was enabled (Vlaisavljević et al., 2008). Moreover, it has been proved in many studies that the transfer of only one blastocyst in a group of patients with the highest probability for conception can result in a similar pregnancy rate as the transfer of two blastocysts, but the proportion of multiple pregnancies is significantly reduced (Gerris et al., 2005). The analysis of outcomes of 904 IVF cycles from four randomized studies and 7404 cycles from six cohort studies showed a pregnancy rate of $33.9 \%$ after elective single embryo-transfers (eSET) and 35\% after double embryo-transfers (DET), and a very high twins rate of $32.6 \%$ in the DET group (Gerris et al., 2005).

The success rate of eSET mainly depends on the ability of selection of the best embryo from all those available. The selection made among blastocysts is easier than selection of early cleavage stage embryos. Nevertheless, the morphology of blastocysts is very heterogeneous and a decision for single or double blastocyst transfer is sometimes very difficult, especially if only morphologically suboptimal blastocysts are available.

\subsection{Transfer outcome in relation to blastocyst morphology}

The analysis was made on 2779 blastocyst transfer cycles performed at the Maribor IVF Centre from 2001 to 2010 in a patient group with female ages of less than 36 and a maximum of one previous IVF attempt. Ovarian stimulation protocols with a combination of GnRH agonist/GnRH antagonist and recombinant FSH (Gonal- ${ }^{\circledR}$, Serono International SA, Geneva, Switzerland)/HMG (Menopur, Ferring Pharmaceuticals Inc., Saint-Prex, Switzerland) were used and described previously in detail (Vlaisavljević et al, 2008). The decision for short or prolonged embryo culture was made on the third day after oocyte insemination. The embryos were cultivated to day 5 if the cohort of day-3 embryos had more than two morphologically optimal embryos containing eight equally-sized blastomeres and less than $10 \%$ of cytoplasmic fragments in the periviteline space. Embryos were cultivated in sequential media (BlastAssist System, Medicult/Origio, Denmark) and were assessed daily by using the conventional grading system for early embryos and our blastocyst grading system (Kovačič et al., 2004). Single (SBT) or double blastocyst transfer (DBT) was selected with the agreement of patients. In 2008, the Health Insurance Institute of Slovenia strove to lower the number of multiple pregnancies. It widened the rights of patients by reimbursing them for two additional IVF cycles, allowing a total of six cycles to be reimbursed. But in women younger than 36, only one top-quality embryo in the first two IVF cycles should be transferred. According to this limitation, elective single blastocyst transfer was favoured from 2008 in this patient group.

The analysis shows similar delivery rates in groups of transfers of single optimal blastocyst, double optimal blastocysts or double optimal + non-optimal blastocysts ( $54.7 \%$ vs. $60.4 \%$ vs. $53.1 \%$; $>>0.05)$.

The twins rate was $51.9 \%$ in the group of double optimal blastocysts and only $10 \%$ less $(41.5 \%)$ in double optimal + non-optimal blastocyst group.

Single non-optimal or double non-optimal blastocyst transfers resulted in equal delivery rates $(32.6 \%$ vs. $34.7 \%)$, but they were significantly lower than the delivery rate obtained in the group of single optimal blastocyst transfers $(54.7 \%)(\mathrm{p}<0.05)$. Nevertheless, the twins rate in double non-optimal blastocyst transfer was still $28 \%$. 
A more detailed analysis of transfers of poor quality blastocysts graded B5 to B8 shows, again, very similar delivery rates after SBT and DBT (29.1\% vs. $26.9 \%)$ and a twins rate of $21.7 \%$ in the DBT group.

\begin{tabular}{|l|c|c|c|c|c|}
\hline & \multicolumn{2}{|c|}{$\begin{array}{c}\text { Single blastocyst } \\
\text { transfer }\end{array}$} & \multicolumn{3}{c|}{$\begin{array}{c}\text { Double blastocyst } \\
\text { transfer }\end{array}$} \\
\hline Blastocyst quality & Optimal & $\begin{array}{c}\text { Non- } \\
\text { optimal }\end{array}$ & $\begin{array}{c}\text { Optimal } \\
\text { Optimal }\end{array}$ & $\begin{array}{c}\text { Optimal } \\
\text { Non- } \\
\text { optimal }\end{array}$ & $\begin{array}{c}\text { Non- } \\
\text { optimal } \\
\text { Non- } \\
\text { optimal }\end{array}$ \\
\hline No. of transfers & 869 & 362 & 555 & 377 & 616 \\
\hline Clinical pregnancies & $546(62.8)$ & $124(34.3)$ & $373(67.2)$ & $227(60.2)$ & $248(40.3)$ \\
\hline Deliveries & $475 \mathbf{( 5 4 . 7 )}$ & $118 \mathbf{( 3 2 . 6 )}$ & $335(\mathbf{6 0 . 4})$ & $200 \mathbf{( 5 3 . 1 )}$ & $214(\mathbf{3 4 . 7})$ \\
\hline Singletons & $469(\mathbf{9 8 . 7})$ & $115(\mathbf{9 7 . 5})$ & $157(46.9)$ & $115(57.5)$ & $154(72)$ \\
\hline Twins & $6 \mathbf{( 1 . 3 )}$ & $3 \mathbf{( 2 . 5 )}$ & $174 \mathbf{( 5 1 . 9 )}$ & $83 \mathbf{( 4 1 . 5 )}$ & $60(\mathbf{2 8 )}$ \\
\hline Triplets & 0 & 0 & $4(1.2)$ & $2(1)$ & 0 \\
\hline
\end{tabular}

Values in parentheses are percentages.

Table 1. Delivery rates after single and double blastocyst transfers in a group of patients younger than 36 with one or fewer previous IVF treatments.

It is clear from previous reports (Henman et al., 2005; Lukassen et al., 2005; Vlaisavljević et al., 2008) that in women 36 years old and younger, where we expect a delivery rate per transfer of more than $30 \%$, transferring two blastocysts will result in an unacceptably high percentage of multiple pregnancies. In some countries (like in Slovenia), the obligation for single embryo-transfer is not only related to patient age but also to embryo quality (for example: elected single embryo-transfer of top quality embryo). Some consider every blastocyst to be a top quality embryo, while others categorize them more precisely and decide for double transfer if blastocysts are not morphologically optimal.

Our blastocyst grading system (Kovačič et al., 2004) consists of 7 morphologically suboptimal blastocyst types, and for each, the expected live birth rate was calculated in a patient group younger than 40 . All the categories of suboptimal blastocysts, graded from B4 to $\mathrm{B} 8 \mathrm{had}$ a live birth rate calculated at lower than $30 \%$. According to the recommendation regarding the limitation of double embryo transfer in cycles with expected delivery rates of more than 30\%, we can conclude that in cases with blastocysts graded B3 and higher, more than one blastocyst could be transferred. However, in our recent study (Table 2), the subpopulation of blastocyst transfers of very poor quality blastocysts was further analyzed. It was proven again that double blastocyst transfer does not improve delivery rate neither in cycles with optimal nor in cycles with very poor quality blastocysts.

One of the main reasons for doubts about the reasonability of single blastocyst transfer in the past was in the relatively low success of the blastocyst-freezing program. The pregnancy rate in European countries was around 15\% per one thawing cycle. This was only half of the pregnancy rate achieved by fresh blastocysts (de Mouzon et al., 2010), but the modification of vitrification techniques in the last couple of years have much improved the survival and live birth rates (Mukaida et al., 2001; Hiraoka et al., 2004; Kuwayama et al., 2005). 


\begin{tabular}{|l|c|c|}
\hline & $\begin{array}{c}\text { Single blastocyst } \\
\text { transfer }\end{array}$ & $\begin{array}{c}\text { Double blastocyst } \\
\text { transfer }\end{array}$ \\
\hline Blastocyst quality & $\mathrm{B} 5-\mathrm{B} 8$ & Both B5-B8 \\
\hline No. of transfers & 172 & 308 \\
\hline Clinical pregnancies & $57(33.1)$ & $99(32.1)$ \\
\hline Deliveries & $50(\mathbf{2 9 . 1 )}$ & $83(\mathbf{2 6 . 9 )}$ \\
\hline Singletons & $50(100)$ & $65(78.3)$ \\
\hline Twins & $0(\mathbf{0})$ & $18(\mathbf{2 1 . 7})$ \\
\hline Triplets & 0 & 0 \\
\hline
\end{tabular}

Values in parentheses are percentages.

Table 2. Delivery and twins rate in a younger patient group after the transfer of one or two blastocysts of poor quality.

\section{Blastocyst morphology after cryopreservation}

Blastocyst is not the optimal stage for cryopreservation. It contains a large amount of liquid in the blastocoel, which must be eliminated before the embryo undergoes cooling. To achieve this, a high concentration of cryoprotectants must be used, despite that they can become toxic to an embryo after a longer exposure time. Vitrification is a two-step technique. In the first step, the blastocyst must be exposed to an equilibration medium, which causes partial dehydration and decreasing in the blastocyst volume and its reexpansion after a couple of minutes. The second step must be performed in one minute. After putting the blastocyst into the vitrification medium, its blastocoel quickly looses liquid. Blastocysts are therefore vitrified in a collapsed stage. When it is warmed, its embryonic mass fills only $50 \%$ of the volume within zona pelucida (Figure 4A). By

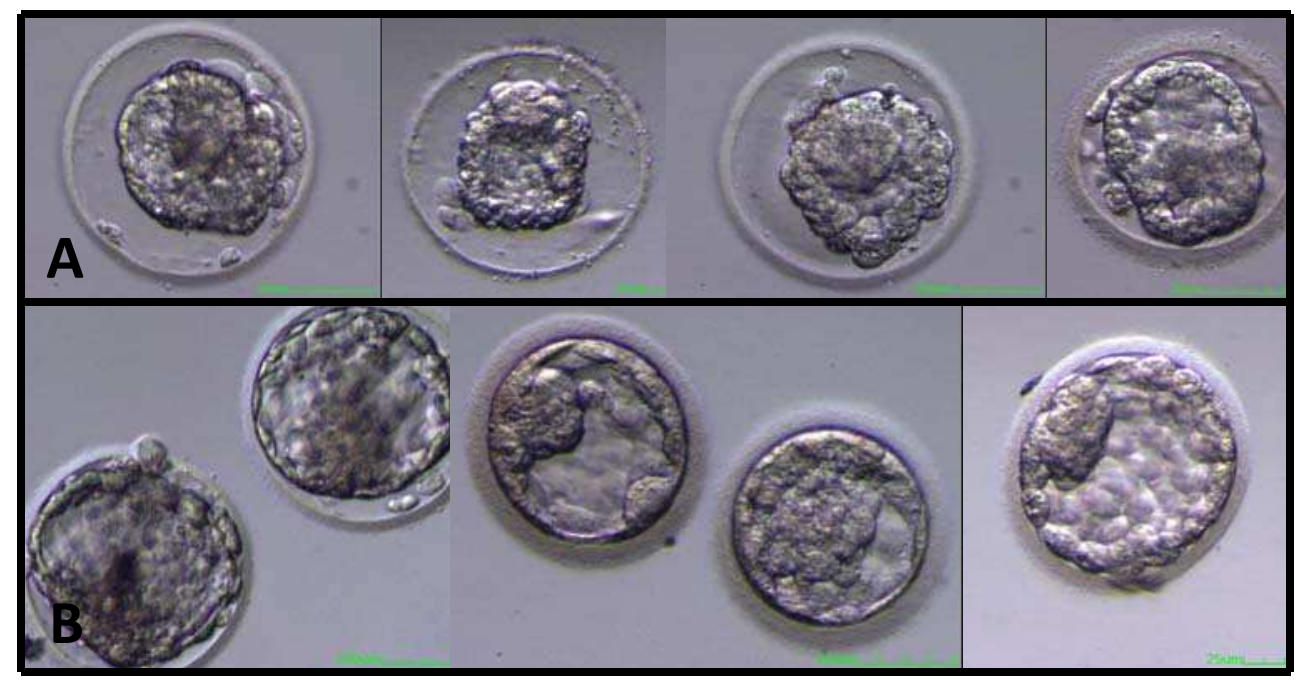

Fig. 4. Blastocysts that completely survived the vitrification/devitrification procedure.

A Blastocysts in the collapsed stage immediately after devitrification. B Re-expanded blastocysts two hours later. 
decreasing the concentration of cryoprotectants stepwise, the blastocyst should recover the volume of trophectoderm cells that they had before cryopreservation. The intracellular organelles must be redistributed forming polarized cells and a functional $\mathrm{Na} / \mathrm{K}$ pump, responsible for filling the blastocoel with liquid. Two hours after warming, a blastocyst should partially or completely re-expand (Figure 4B) to the dimensions it had before vitrification. If the blastocyst survives, its ICM must be equally shaped and sized as before cryopreservation.

\subsection{Impact of blastocyst expansion on survival after vitrification}

Fresh blastocysts are heterogeneous in morphology and in the ability to survive vitrification. The aim of our study was to find out the implantation ability of various blastocyst types after vitrification, warming and embryo replacement (VER) and to estimate the prediction of live birth after VER.

Day-5 surplus blastocysts or compact morulae from IVF/ICSI cycles were scored before vitrification by using our grading system (Kovačič et al., 2004) (Figure 3). Surplus blastocysts were vitrified in Cryo Bio System Vitrification straws (France) by using Irvine Scientific (USA) Vitrification protocol and media. Blastocysts were frozen individually, thus, their quality (grade) was known when they were thawed.

Warmed blastocysts were replaced in natural cycles $(n=327)$ or in cycles supported by estrogen/progesterone $(n=103)$. In our retrospective study, we analyzed 430 devitrification cycles in which 750 blastocysts were devitrified and 642 (85.6\%) embryos survived and were replaced.

\begin{tabular}{|c|c|c|c|c|}
\hline \multicolumn{2}{|c|}{$\begin{array}{c}\text { Types of blastocysts before } \\
\text { vitrification }\end{array}$} & $\begin{array}{c}\text { Expanded } \\
\text { Blastocysts }\end{array}$ & $\begin{array}{c}\text { Early } \\
\text { blastocysts }\end{array}$ & $\begin{array}{c}\text { Poor } \\
\text { blastocysts }\end{array}$ \\
\hline \multirow{2}{*}{\multicolumn{2}{|c|}{$\begin{array}{l}\text { Number of warmed } \\
\text { blastocysts }(n) \\
\text { Morphology of warmed } \\
\text { blastocysts } \\
\end{array}$}} & 552 & 97 & 101 \\
\hline & & & & \\
\hline $\mathrm{a}$ & $\begin{array}{l}100 \% \text { intact, re- } \\
\text { expanded }(n)\end{array}$ & $224(40.6)$ & 63 (64.9) & 38 (37.6) \\
\hline $\mathrm{b}$ & $\begin{array}{l}<100 \%>50 \% \text { intact, } \\
\text { re-expanded }(n)\end{array}$ & $200(36.2)$ & $21(21.6)$ & $32(31.7)$ \\
\hline C & $\begin{array}{l}<100 \%>50 \% \text { intact, } \\
\text { non-expanded }(n)\end{array}$ & $40(7.2)$ & $7(7.2)$ & 17 (16.8) \\
\hline $\mathrm{d}$ & Damaged $(n)$ & $88(15.9)$ & $6(6.2)$ & $14(13.9)$ \\
\hline \multicolumn{2}{|c|}{$\begin{array}{l}\text { Survival } \\
\text { rate }(\mathrm{a}+\mathrm{b}+\mathrm{c})(\%)\end{array}$} & 84.0 & 93.8 & 86.1 \\
\hline \multicolumn{2}{|c|}{$\begin{array}{l}\text { Live births/warmed } \\
\text { blastocysts (\%) }\end{array}$} & $\begin{array}{c}82 / 552 \\
(14.9)\end{array}$ & $\begin{array}{l}14 / 97 \\
(14.4)\end{array}$ & $\begin{array}{c}8 / 101 \\
(7.9)\end{array}$ \\
\hline \multicolumn{2}{|c|}{$\begin{array}{l}\text { Live births/transferred } \\
\text { blastocysts }(\%)\end{array}$} & $\begin{array}{c}82 / 464 \\
(\mathbf{1 7 . 7 )}\end{array}$ & $\begin{array}{l}14 / 91 \\
(15.4)\end{array}$ & $\begin{array}{l}8 / 87 \\
(9.2)\end{array}$ \\
\hline
\end{tabular}

Values in parenthesis are percentages.

Table 3. Survival and live birth rates after vitrification in variously expanded blastocyst groups. 
All warmed blastocysts were assessed for morphology, first, immediately after warming and second, two hours later, before the transfer was performed. Warmed blastocysts were categorized into four groups (A-D), considering the proportion of intact cells and the ability of re-expansion. A were blastocysts with $100 \%$ intact cells and re-expansion within two hours after cryopreservation. B were blastocysts with less than $100 \%$ and more than $50 \%$ of intact cells with the ability to re-expand the blastocoel. C contained blastocysts that remained non-expanded even after two hours of incubation after thawing. D blastocysts degenerated or had less than $50 \%$ of intact cells.

Survival (more than $50 \%$ of intact cells), optimal survival $(100 \%$ of intact cells and reexpansion), implantation (gestational sac with heart beats) and live birth rates were calculated for all three groups of warmed blastocysts for which the outcome after replacement was known (98.4\% of all transferred blastocysts).

Blastocysts with optimal survival (a) contained all cells intact and were able to refill the blastocoel and expand after two hours of incubation. The rates of optimal survival differ significantly between expanded blastocysts (40.6\%) and non-expanded blastocysts $(64.9 \%)$ $(\mathrm{P}<0.0001)$. Among poor blastocysts, only $37.6 \%$ of them completely survived vitrification.

By regarding overall survival rates (at least $50 \%$ of intact cells), those embryos with no blastocoel or with the beginning of cavitation survived vitrification better than morphologically optimal blastocysts with expanded blastocoel and normal TE and ICM $(\mathrm{P}<0.05)$. The same has been reported by Van Landuyt et al. (2011). The survival rates in their study were higher for early blastocysts $(86.7 \%)$ compared to full $(78.7 \%)$ or expanded blastocysts $(72.7 \%)$. Similar results were also obtained by Cho et al., 2002; Vandezwalmen et al., 2002; Mukaida et al., 2006; and Ebner et al., 2009. This is probably due to lower permeability of later blastocyst stages to the cryoprotectant (Cho et al., 2002; Vanderzwalmen et al., 2002).

\subsection{Live birth rates after vitrification of variously expanded blastocysts}

Meta analysis of studies comparing transfer outcomes of slowly frozen/thawed and vitrified/warmed embryos and blastocysts showed significantly better clinical results in the vitrification group (Loutradi et al., 2008). Vitrification is becoming an increasingly popular method of cryopreservation due to simplification of the procedure. It is evident that this method improved survival and implantation rates, especially in the blastocyst cryopreservation program. There are some technical details with great impact on blastocyst survival. First, expanded blastocysts are sometimes more difficult to equilibrate with cryoprotectant than other stage embryos, thus, exposure to equilibration solution should be modified from embryo to embryo depending on its expansion rate. However, all procedures are time limited due to possible toxic effects in cases of longer incubation of embryos in cryoprotectant. Secondly, faster rates of cooling and warming can be achieved by minimizing the volume of the cryoprotectant with which embryos are vitrified. Most published studies on blastocyst vitrification present survival rates that are higher than $85 \%$ (Mukaida and Takahashi, 2007). However, there are still big differences in implantation and pregnancy rates among published studies.

Mukaida and Takahashi (2007) achieved a pregnancy rate per warming of $48.4 \%$ and an implantation rate of $38.5 \%$ in 1500 warming cycles with 3500 warmed blastocysts by using the 
cryoloop technique. They much improved their results when artificial shrinkage was applied in expanded blastocysts before vitrification (60\% pregnancy and $48 \%$ implantation rate).

Goto et al. (2011) demonstrated that there was a significant correlation between fresh blastocyst score and pregnancy outcome after vitrification, warming and transfer of blastocysts. The highest delivery rate was observed in the fully-expanded and hatching blastocyst group of transfers and the lowest success with early blastocysts (59.9\% vs. $4.5 \%)$ in the young patient group. They reported the same success rate as is usually achieved with fresh optimal blastocysts. The blastocysts in this study were vitrified in open straws with a cooling rate of $-23000^{\circ} \mathrm{C} / \mathrm{min}$.

In our study, we used closed vitrification straws, according to EU Directives concerning tissue and cell storage, in which the blastocysts were vitrified with a cooling rate of approximately $-2000^{\circ} \mathrm{C} / \mathrm{min}$. Our delivery rates in the expanded blastocyst group deviate a lot from Goto's results $(17.7 \%)$. We can't explain the difference in success rates with different cooling rates used in both studies, since some experiments have already demonstrated that the success rate of blastocyst vitrification in a closed or open system can be the same (Guns et al., 2008). The results from our study are completely comparable with results from the Belgian group (Van Landuyt et al., 2011) in which the vital clinical pregnancy rate per transferred full blastocyst was around $17.5 \%$ and per transferred early blastocyst was $10.6 \%$.

In our and in Belgian studies, the blastocysts for vitrification were not rigorously preselected. Besides this, the difference from the Japanese studies is also in their waiting for blastocoels expansion or spontaneous hatching of blastocysts and in performing assisted collapsing before vitrification. All these details could be crucial for success, but their impact should be further investigated.

\section{Conclusions}

The calculated implantation ability of specific blastocyst type should help the clinicians in their decision regarding the number of fresh or frozen/thawed blastocysts for transfer and in predicting implantation and live birth after the transfer. Our results showed that single or double blastocyst transfer result in similar pregnancy rates in young patient groups, but the twin rate remains unacceptably high after the transfer of two blastocysts, especially if at least one of them is morphologically optimal. Double blastocyst transfer is therefore not advised in young patient groups.

Vitrification is a cryopreservation method for surplus blastocysts. It seems that nonexpanded blastocysts are a more optimal stage for vitrification than expanded blastocysts, since the former survive vitrification at higher rates. Nevertheless, the implantation abilities of devitrified early blastocysts or expanded blastocysts were comparable, but significantly lower when compared to fresh blastocysts. It is not clear yet if the differences in success rates after the transfer of devitrified blastocysts between studies are the result of various preselection criteria for blastocysts suitable for vitrification or that there are details in vitrification techniques that are crucial for embryo survival and implantation. Further studies are required for analysis of the effect of open or closed vitrification systems, different cryopreservation media, assisted collapsing and times of exposing the embryos to vitrification solutions. 


\section{References}

Abe, H. Otoi, T. Tachikawa, S. Yamashita, S. Satoh, T \& Hoshi, H. (1999). Fine structure of bovine morulae and blastocysts in vivo and in vitro. Anatomy and Embryology, Vol.199(6), pp. 519-527

Balaban, B. Urman, B. Sertac, A. Alatas, C. Aksoy, S \& Mercan, R. (2000). Blastocyst quality affects the success of blastocyst-stage embryo transfer. Fertility and Sterility, Vol.74, pp. 282-287

Barrenetxea, G. López de Larruzea, A. Ganzabal, T. Jiménez, R. Carbonero, K \& Mandiola, M. (2005). Blastocyst culture after repeated failure of cleavage-stage embryo transfers: a comparison of day 5 and day 6 transfers. Fertility and Sterility, Vol.83(1), pp. $49-53$

Braude, P. Bolton, V \& Moore, S. (1988). Human gene expression first occurs between the four- and eight-cell stages of preimplantation development. Nature, Vol.332(6163), pp. 459-61

Cho, H.J. Son, W.Y. Yoon, S.H. Lee, S.W. \& Lim, J.H. (2002). An improved protocol for dilution of cryoprotectants from vitrified human blastocysts. Human Reproduction, Vol.17(9), pp. 2419-2422

Conagham, J. Hardy, K. Handyside, A.H., Winston, R.M. \& Leese, H.J. (1993). Selection criteria for human embryo transfer: a comparison of pyruvate uptake and morphology. Journal of Assisted Reproduction and Genetic, Vol.10, pp. 21-30

Croxatto, H.B. Ortiz, M.E. Díaz, S. Hess, R. Balmaceda, J. \& Croxatto, H.D. (1978). Studies on the duration of egg transport by the human oviduct. II. Ovum location at various intervals following luteinizing hormone peak. American Journal of Obstetrics and Gynecology, Vol.132(6), pp. 629-634

Dardik, A. Doherty, A.S. \& Schultz, R.M. (1993). Protein secretion by the mouse blastocyst: stimulatory effect on secretion into the blastocoel by transforming growth factoralpha. Molecular Reproduction and Development, Vol.34(4), pp. 396-401

De Mouzon, J. Goossens, V. Bhattacharya, S. Castilla, J.A. Ferraretti, A.P. Korsak, V. Kupka, M. Nygren, K.G. Nyboe Andersen. A. \& The European IVF-monitoring (EIM) Consortium. (2010). Assisted reproductive technology in Europe, 2006: results generated from European registers by ESHRE. Human Reproduction, Vol.25, pp. 1851-1862

Dokras, A. Sargent, I.L. \& Barlow, D.H. (1993). Human blastocyst grading: an indicator of developmental potential. Human Reproduction, Vol.8, pp. 2119-2127

Ducibella, T. Albertini, D.F. Anderson, E. \& Biggers, J.D. (1975). The preimplantation mammalian embryo: characterization of intercellular junctions and their appearance during development. Developmental Biology, Vol.45(2), pp. 231-250

Ebner, T. Gruber, I \& Moser, M. (2004). Location of herniation predicts implantation behaviour of hatching blastocysts. Journal of the Turkish-German Gynecological Association, Vol.8, pp. 184-189

Ebner, T. Vanderzwalmen, P. Shebl, O. Urdl, W. Moser, M. Zech, NH \& Tews, G. (2009). Morphology of vitrified/warmed day-5 embryos predicts rates of implantation, pregnancy and live birth. Reproductive Biomedicine Online, Vol.19(1), pp. 72-78

Gardner, D. Vella, P. Lane, M. Wagley, L. Schlenker, T \& Schoolcraft, W. (1998). Culture and transfer of human blastocysts increases implantation rates and reduces the need for multiple embryo transfers. Fertility and Sterility, Vol.69, pp. 84-88 
Gardner, D.K. \& Lane, M. (1997). Culture and selection of viable human blastocysts: a feasible proposition for human IVF. Human Reproduction Update, Vol.3, pp. 367-382

Gardner, D.K. \& Schoolcraft, WB. (1999). In vitro culture of human blastocysts. In: Jansen R, Mortimer D (eds) Toward reproductive certainty: fertility and genetics beyond. Parthenon Publishing, Carnforth, UK. pp. 378-388

Gardner, D.K. Lane, M. Stevens, J. \& Schoolcraft, WB. (2001). Nonivasive assessment of human embryo nutrient consumption as a measure of developmental potential. Fertility and Sterility, Vol.76, pp. 1175-1180

Gardner, D.K. Lane, M. Stevens, J. Schlenker, T. \& Schoolcraft, W.B. (2000). Blastocyst score affects implantation and pregnancy outcome: towards a single blastocyst transfer. Fertility and Sterility, Vol.73(6), pp. 1155-1158

Gardner, D.K. Lane, M.W. \& Lane, M. (2000). EDTA stimulates cleavage stage bovine embryo development in culture but inhibits blastocyst development and differentiation. Molecular Reproduction and Development, Vol.57, pp. 256-261

Gardner, D.K. Pool, T.B. \& Lane, M. (2000). Embryo nutrition and energy metabolism and its relationship to embryo growth, differentiation, and viability. Seminars in Reproductive Medicine, Vol.18(2), pp. 205-218

Garrod, D. Chidgey, M. \& North, A. (1996). Desmosomes: differentiation, development, dynamics and disease. Current Opinion in Cell Biology, Vol.8(5), pp. 670-678

Gerris, J.M. (2005). Single embryo transfer and IVF/ICSI outcome: a balanced appraisal. Human Reproduction Update, Vol.11, pp. 105-121

Goto, S. Kadowaki, T. Tanaka, S. Hashimoto, H. Kokeguchi, S \& Shiotani, M. (2011). Prediction of pregnancy rate by blastocyst morphological score and age, based on 1,488 single frozen-thawed blastocyst transfer cycles. Fertility and Sterility, Vol.95(3), pp. $948-952$

Gualtieri, R. Santella, L \& Dale, B. (1992). Tight junctions and cavitation in the human preembryo. Molecular Reproduction and Development, Vol.32(1), pp. 81-87

Guns, Y. Vandermonde, A. Vitrier, S. Sterckx, J. Devroey, P. Van den Abbeel, E. \& Van Der Elst, J. (2008). Validation of media and devices for vitrification of human embryos: in search of an optimum. In: Abstracts of the 24th Annual Meeting of the ESHRE, Barcelona, Spain, O-134, pp. i55-i56

Henman, M. Catt, J.W. Wood, T. Bowman, M.C. de Boer, K.A. \& Jansen, R.P. (2005). Elective transfer of single fresh blastocysts and later transfer of cryostored blastocysts reduces the twin pregnancy rate and can improve the in vitro fertilization live birth rate in younger women. Fertility and Sterility, Vol.84, pp. 1620-1627

Hiraoka, K. Hiraoka, K. Kinutani, M \& Kinutani, K. (2004). Blastocoele collapse by micropipetting prior to vitrification gives excellent survival and pregnancy outcomes for human day 5 and 6 expanded blastocysts. Human Reproduction, Vol.19, pp. 2884-2888

Houghton, F.D. (2006). Energy metabolism of the inner cell mass and trophectoderm of the mouse blastocyst. Differentiation, Vol.74, pp. 11-18

Houghton, F.D. Hawkhead, JA. Humpherson, PG. Hogg, JE. Balen, AH. Rutherford, AJ \& Leese, HJ. (2002). Non-invasive amino acid turnover predicts human embryo developmental capacity. Human Reproduction, Vol.17, pp. 999-1005 
Ivec, M. Kovačič, B \& Vlaisavljević, V. (2011). Prediction of human blastocyst development from morulae with delayed and/or uncomplete compaction. Fertility and Sterility, (In Press).

Kovacic, B. \& Vlaisavljevic, V. (2008). Influence of atmospheric versus reduced oxygen concentration on development of human blastocysts in vitro: a prospective study on sibling oocytes. Reproductive Biomedicine Online, Vol.17, pp. 229-236

Kovačič, B. Sajko, M.C. \& Vlaisavljević, V. (2010). A prospective, randomized trial on the effect of atmospheric versus reduced oxygen concentration on the outcome of intracytoplasmic sperm injection cycles. Fertility and Sterility, Vol.94, pp. 511-519

Kovacic, B. Vlaisavljevic, V. Reljic, M. \& Cizek-Sajko, M. (2004). Developmental capacity of different morphological types of day 5 human morulae and blastocysts. Reproduction Biomedicine Online, Vol.8, pp. 687-694

Kuwayama, M. Vajta, G. Ieda, S \& Kato, O. (2005). Comparison of open and closed methods for vitrification of human embryos and the elimination of potential contamination. Reproductive Biomedicine Online, Vol.11, pp. 608-614

Leese, H.J. Conaghan, J. Martin, KL \& Hardy, K. (1993). Early human embryo metabolism. Bioessays, Vol.15, pp. 259-264

Lesny, P. Killick, S.R. Tetlow, R.L. Robinson, J. \& Maguiness, S.D. (1998). Uterine junctional zone contractions during assisted reproduction cycles. Human Reproduction Update, Vol.4(4), pp. 440-445

Loutradi, K.E. Kolibianakis, E.M. Venetis, C.A. Papanikolaou, E.G. Pados, G. Bontis, I. \& Tarlatzis, B.C. (2008). Cryopreservation of human embryos by vitrification or slow freezing: a systematic review and meta-analysis. Fertility and Sterility, Vol.90, pp. 186-193

Lukassen, H.G. Braat, D.D. Wetzels, A.M. Zeilhuis, G.A. Adang, E.M. Scheenjes, E. \& Kremer, J.A. (2005). Two cycles with single embryo transfer versus one cycle with double embryo transfer: a randomized controlled trial. Human Reproduction, Vol.20, pp. $702-708$

Mukaida, T \& Takahashi, K. (2007). Vitrification of blastocysts using the Cryoloop technique. In Tucker MJ, Lieberman J (eds.) Vitrification in assisted reproduction, Informa Healthcare, London, pp. 219-238

Mukaida, T. Nakamura, S. Tomiyama, T. Wada, S. Kasai, M. \& Takahashi, K. (2001). Successful birth after transfer of vitrified human blastocysts with use of a cryoloop containerless technique. Fertility and Sterility, Vol.76, pp. 618-620

Mukaida, T. Oka, C. Goto, T. \& Takahashi, K. (2006). Artificial shrinkage of blastocoeles using either a micro-needle or a laser pulse prior to the cooling steps of vitrification improves survival rate and pregnancy outcome of vitrified human blastocysts. Human Reproduction, Vol.21(12), pp. 3246-3252

Richter, K.S. Harris, D.C. Daneshmand, S.T. \& Shapiro, B.S. (2001). Quantitative grading of a human blastocyst: optimal inner-cell mass size and shape. Fertility and Sterility, Vol.76, pp. 1157-1167

Schieve, L.A. Peterson, H.B. Meikle, S.F. Jeng, G. Danel, I. Burnett, N.M. \& Wilcox, L.S. (1999). Live-birth rates and multiple-birth risk using in vitro fertilization. JAMA, Vol.282, pp. $1832-1838$

Scott, L.A. (2000). Oocyte and embryo polarity. Seminars in Reproductive Medicine, Vol.18, pp. 171-183 
Shapiro, B.S. Daneshmand, S.T. Garner, F.C. Aguirre, M. \& Ross, R. (2008). Contrasting patterns in in vitro fertilization pregnancy rates among fresh autologous, fresh oocyte donor, and cryopreserved cycles with the use of day 5 or day 6 blastocysts may reflect differences in embryo-endometrium synchrony. Fertility and Sterility, Vol.89(1), pp. 20-26

Shapiro, B.S. Richter, K.S. Harris, D.C \& Daneshmand, S.T. (2001). A comparison of day 5 and day 6 blastocyst transfers. Fertility and Sterility, Vol.75, pp. 1126-1130

Shoukir, Y. Chardonnens, D. Campana, A. Bischof, P \& Sakkas, D. (1998). The rate of development and time of transfer play different roles in influencing the viability of human blastocysts. Human Reproduction, Vol.13, pp. 676-681

Stojkovic, M. Kolle, S. Peinl, S. Stojkovic, P. Zakhartchenko, V. Thompson, JG. Wenigerkind, H. Reichenbach, H.D. Sinowatz, F. \& Wolf, E. (2002). Effect of high concentrations of hyaluronan in culture medium on development and survival rates of fresh and frozen-thawed bovine embryos produced in vitro. Reproduction, Vol.124, pp. 141153

Summers, M.C. \& Biggers, J.D. (2003). Chemically defined media and the culture of mammalian preimplantation embryos: historical perspective and current issues. Human Reproduction Update, Vol.9, pp. 557-582

Van Landuyt, L. Stoop, D. Verheyen, G. Verpoest, W. Camus, M. Van de Velde, H. Devroey, P \& Van den Abbeel, E. (2011). Outcome of closed blastocyst vitrification in relation to blastocyst quality: evaluation of 759 warming cycles in a single-embryo transfer policy. Human Reproduction, Vol.26, pp. 527-534

Vanderzwalmen, P. Bertin, G. Debauche, C.H. Standaert, V. van Roosendaal, E. Vandervorst, M. Bollen, N. Zech, H. Mukaida, T. Takahashi, K \& Schoysman, R. (2002). Births after vitrification at morula and blastocyst stages: effect of artificial reduction of the blastocoelic cavity before vitrification. Human Reproduction, Vol.17(3), pp. 744-751

Veeck, L. \& Zaninovic, N. (2009). Human blastocysts in vitro. In: Veeck L, Zaninovic N, eds. An Atlas of Human Blastocysts. Boca Raton, London, New York, Washington: Parthenon Publishing, pp. 99-137.

Veeck, L.L. (2003). Does the developmental stage at freeze impact on clinical results postthaw? Reproductive Biomedicine Online, Vol.6(3), pp. 367-374

Vlaisavljevic, V. Dmitrovic, R. \& Sajko, M.C. (2008). Should the practice of double blastocyst transfer be abandoned? A retrospective analysis. Reproduction Biomedicine Online, Vol.16, pp. 677-683

Watson, A.J. \& Kidder, G.M. (1988). Immunofluorescence assessment of the timing of appearance and cellular distribution of $\mathrm{Na} / \mathrm{K}$-ATPase during mouse embryogenesis. Developmental Biology, Vol.126(1), pp. 80-90

Watson, AJ. (1992). The cell biology of blastocyst development. Molecular Reproduction and Development, Vol.33, pp. 492-504

Yoon, H.J. Yoon, S.H. Son, W.Y. Im, K.S. \& Lim, J.H. (2001). High implantation and pregnancy rates with transfer of human hatching day 6 blastocysts. Fertility and Sterility, Vol.75, pp. 832-833 


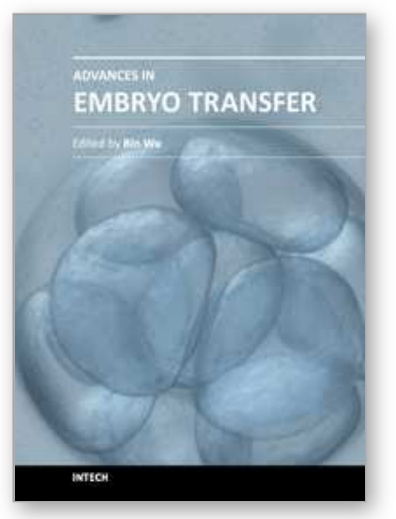

\author{
Advances in Embryo Transfer \\ Edited by Dr. Bin Wu
}

ISBN 978-953-51-0318-9

Hard cover, 248 pages

Publisher InTech

Published online 14, March, 2012

Published in print edition March, 2012

Embryo transfer has become one of the prominent high businesses worldwide. This book updates and reviews some new developed theories and technologies in the human embryo transfer and mainly focus on discussing some encountered problems during embryo transfer, which gives some examples how to improve pregnancy rate by innovated techniques so that readers, especially embryologists and physicians for human IVF programs, may acquire some new and usable information as well as some key practice techniques. Major contents include the optimal stimulation scheme for ovaries, advance in insemination technology, improved embryo transfer technology and endometrial receptivity and embryo implantation mechanism. Thus, this book will greatly add new information for readers to improve human embryo transfer pregnancy rate.

\title{
How to reference
}

In order to correctly reference this scholarly work, feel free to copy and paste the following:

Borut Kovačič and Veljko Vlaisavljević (2012). Importance of Blastocyst Morphology in Selection for Transfer, Advances in Embryo Transfer, Dr. Bin Wu (Ed.), ISBN: 978-953-51-0318-9, InTech, Available from: http://www.intechopen.com/books/advances-in-embryo-transfer/importance-of-blastocyst-morphology-inselection-for-transfer

\section{INTECH}

open science | open minds

\section{InTech Europe}

University Campus STeP Ri

Slavka Krautzeka 83/A

51000 Rijeka, Croatia

Phone: +385 (51) 770447

Fax: +385 (51) 686166

www.intechopen.com

\section{InTech China}

Unit 405, Office Block, Hotel Equatorial Shanghai

No.65, Yan An Road (West), Shanghai, 200040, China

中国上海市延安西路65号上海国际贵都大饭店办公楼405单元

Phone: +86-21-62489820

Fax: +86-21-62489821 
(C) 2012 The Author(s). Licensee IntechOpen. This is an open access article distributed under the terms of the Creative Commons Attribution 3.0 License, which permits unrestricted use, distribution, and reproduction in any medium, provided the original work is properly cited. 